\title{
A nationwide assessment of lifestyle medicine counseling: knowledge, attitudes, and confidence of Israeli senior family medicine residents
}

\author{
Lilach Malatskey ${ }^{1,2,3^{*}}$ D, Yael Bar Zeev ${ }^{4}$, Rani Polak ${ }^{5,6}$, Adva Tzuk-Onn $^{1}$ and Erica Frank ${ }^{3,7}$
}

\begin{abstract}
Background: Non-communicable diseases are the leading causes of death, largely due to the last century's oftenunhealthy lifestyles. Family medicine (FM) and other physicians can improve patients' lifestyle behaviors, yet FM residency programs in Israel and other countries do not uniformly deliver lifestyle medicine (LM) training. The readiness of FM residents to counsel on lifestyle issues is not known. The purpose of this study is to assess knowledge, attitudes, and confidence levels of senior Israeli FM residents regarding LM counseling, and to evaluate the influence of LM training and personal health behaviors on residents' LM knowledge, attitudes, and confidence.

Methods: From May to June 2017, we surveyed all senior Israeli FM residents regarding their knowledge, attitudes, confidence, and personal health behaviors. We compared health behaviors, attitudes, and confidence in counselling between: 1) trained residents vs. untrained residents; 2) physically active residents vs. not physically active residents; 3 ) residents with a $\mathrm{BMl}<25$ vs. those with a $\mathrm{BMI}>25$; and 4) residents who eat a Mediterranean diet vs. those who do not.

Results: A total of 169 senior Israeli FM residents were surveyed, and 143 completed the survey, a response rate of $84.6 \%$. Senior FM residents said they considered LM counseling to be an integral part of their role and an effective tool by which to improve a patient's health. Yet, their knowledge of LM and their confidence in delivering LM counseling are low. Compared with untrained residents $(n=84)$, LM-trained residents $(n=55)$ had higher knowledge scores $(30.9 \%$ vs. $13.1 \%, p=0.016)$ and were more confident in their ability to impact their patients' behaviors ( $53.7 \%$ vs. $34.5 \%, p=0.004)$. Residents' positive personal health behaviors correlated with a higher level of confidence to provide LM counseling.

(Continued on next page)
\end{abstract}

\footnotetext{
* Correspondence: Lilach.Malatskey@gmail.com; LMalatskey@NextGenU.org ${ }^{1}$ Israeli Society of Lifestyle Medicine, Israeli Association of Family Physicians, Tel Aviv, Israel

${ }^{2}$ Siaal Research Center for Family Medicine and Primary Care, Department of Family Medicine, Faculty of Health Sciences, Ben-Gurion University of the Negev, POB 653, 84105 Beer-Sheva, Israel

Full list of author information is available at the end of the article
}

(c) The Author(s). 2020 Open Access This article is licensed under a Creative Commons Attribution 4.0 International License, which permits use, sharing, adaptation, distribution and reproduction in any medium or format, as long as you give appropriate credit to the original author(s) and the source, provide a link to the Creative Commons licence, and indicate if changes were made. The images or other third party material in this article are included in the article's Creative Commons licence, unless indicated otherwise in a credit line to the material. If material is not included in the article's Creative Commons licence and your intended use is not permitted by statutory regulation or exceeds the permitted use, you will need to obtain permission directly from the copyright holder. To view a copy of this licence, visit http://creativecommons.org/licenses/by/4.0/. The Creative Commons Public Domain Dedication waiver (http://creativecommons.org/publicdomain/zero/1.0/) applies to the data made available in this article, unless otherwise stated in a credit line to the data. 
(Continued from previous page)

Conclusions: FM physicians can play a key role in the management of patients with chronic diseases. Israeli FM residents consider counseling patients about a healthy lifestyle to be an integral part of their work, but do not feel well prepared to do so.

Dedicated LM training and resident's personal health promotion may improve critically important levels of LM counseling and patient outcomes, and this training should therefore become a higher priority.

Keywords: Lifestyle medicine, Family medicine, Residents, Educational program, Lifestyle medicine course, Health behavior

\section{Background}

Non-communicable diseases (NCDs) are leading causes of death globally due, to a large extent, to unhealthy lifestyle choices of the last century [1].

In 2015, seven of the ten leading causes of death in Israel were NCDs [2]. Contrary to recommendations, an estimated $19.7 \%$ of the adult population smoked, $53.5 \%$ were overweight or obese, only $18.9 \%$ consumed at least five servings of vegetables and fruits per day, and only $35.2 \%$ routinely fulfilled physical activity recommendations [3].

More than $40 \%$ of chronic conditions could be avoided through the adoption of healthy lifestyle recommendations, according to Mokdad et al. [4], with data from the Nurses' Health Study (1980-2014; $n=78,865)$ and the Health Professionals Follow-up Study (1986-2014, $n=44$, 354) suggesting that healthy lifestyles could substantially reduce premature mortality in U.S. adults. This would require healthier lifestyle habits such as not smoking, maintaining a body mass index (BMI) of 18.5 to $24.9 \mathrm{~kg} / \mathrm{m}^{2}$, participating in at least $30 \mathrm{~min}$ most days of moderate to vigorous physical activity, drinking only moderate amounts of alcohol, and having a high diet quality score (upper 40\%) [5].

Physicians have the ability to influence patients' lifestyle behaviors [6-8] In a randomized controlled trial in four community-based group family medicine clinics in southeastern Missouri (adult patients, - $N=915$ ), a physician's advice was a catalyst for changes made by patients, such as quitting smoking, eating less fat, or getting more exercise, prior to receiving intervention materials on the same topic [8].

Nevertheless, most physicians do not routinely advise on lifestyle behavior changes during medical clinic visits [6, 9-11]. Healthy Israel 2020 places primary care physicians at the forefront of health promotion and preventive medicine [12]. This can be achieved by incorporating Lifestyle Medicine (LM) as part of routine clinical work and medical education programs $[13,14]$.

Physicians' personal health behaviors are also related to patients' health behaviors $[15,16]$. Counseling by a physician is strongly and consistently related to the physician's own health practices, so addressing those practices is key to increasing health promotion counseling in practice. Patients also find physicians who briefly relate that they have such healthier habits more credible and more motivating [17].

In 2015, the World Medical Association recommended [18] that national medical associations "should recognize the strong and consistent link between physicians' and patients' personal health practices, providing yet another critically important reason for health systems to promote physician health" and that physicians' "workplaces should promote conditions conducive to healthy lifestyles, including access to healthy food choices, exercise, nutrition counseling and support for smoking cessation."

A scientific statement from the American Heart Association published in 2016 recommended that all primary care residencies would benefit from incorporating lifestyle modules into their training programs [19]. The American College of Lifestyle Medicine recently launched a LM Residency Curriculum, starting its beta version application in July 2018 at four selected pilot sites [20].

The Israeli syllabus [21] for LM was developed in 2014. Since then, the Israeli Society of Lifestyle Medicine has promoted LM syllabus-based teaching in Israel. In Israel, there are five centers with Family Medicine (FM) residency programs delivering an academic diploma course of three to 4 years of weekly study days. Even though LM curricula are considered important and have been implemented in some of the FM residency programs in Israel, we know little about residents' LM knowledge attitude nor their confidence in delivering LM counseling.

\section{Study aims}

The aims of this study are 1) to assess the knowledge level, attitudes, and confidence of senior Israeli FM residents regarding LM counseling, and 2) to evaluate the influence of training in an LM course and the influence of personal health behaviors on residents' knowledge, attitudes, and confidence regarding LM counseling.

\section{Methods}

Study design and participants

The study is a cross-sectional study. 


\section{Participants}

All FM residents are required to attend an academic diploma course, held at five different sites. All senior Israeli FM residents (those in their third or fourth years of a 4 year Israeli FM residency, $n=169$ ) were included; these sites cover all geographic regions in Israel and include residents from all Israeli Health Maintenance Organizations (HMOs). LM training is usually delivered during the second year of residency or later.

\section{Procedure}

A manual survey was provided by the researcher during one of the diploma course sessions for self-completion in one to three waves until all attended residents had completed the survey (May-June 2017). Residents were not required to provide any identifying information, and voluntary survey completion implied consent.

\section{Survey}

Questions focused on participants' self-reported attitudes and confidence about LM counseling, personal lifestyle behaviors, previous exposure to LM education, and LM knowledge assessment.

Knowledge assessment included ten questions either from FM board examinations (2010-2013) or from experts in each field. Missing answers were considered incorrect. Answering at least seven questions correctly was considered a passing level of knowledge. A score of $60 \%$ or less was considered failing the knowledge test.

Participants' self-reported attitudes and confidence toward LM counseling was assessed by the Lifestyle Questionnaire. This validated questionnaire was developed to assess FM current status (internal reliability $\mathrm{a}=0.84$ ) [22]; the questionnaire was used in a similar population in our previous study [23]. This instrument included the following: (1) thirteen items assessing attitudes regarding LM on a four-point Likert scale ( $1=$ absolutely disagree; $4=a b-$ solutely agree; $\alpha=0.78$ ), further dichotomized as agree (absolutely agree plus agree) versus disagree (absolutely disagree plus disagree), (2) nine items assessing perceived confidence regarding LM counseling on a four-point Likert scale $(1=$ absolutely not confident; 4 = absolutely confident; $\alpha=0.82$ ). Composite mean scores, a serial variable, were also measured for all attitude items combined and for all confidence items combined.

Lifestyle behaviors were assessed using the physician's health questionnaire [24]. This questionnaire was developed to assess the health behavior of Israeli physicians and was subjected to internal validation by an expert panel and a convenience sample of 30 respondents. It previously had been used in an unpublished study with 4832 Israeli physicians. Topics included perceived physical activity (minutes per week aerobic activity), nutrition (days per week consuming a Mediterranean diet, which is characterized by a high intake of plant-based foods [vegetables, legumes, fruits, nuts, cereals (mainly whole grain)], olive oil as the main source of fat, moderate amounts of dairy [yoghourt and cheese], low or moderate consumption of fish and meat, and moderate consumption of wine consumed with meals [25]), processed food consuming, $>=5$ servings of fruit and vegetable servings consumed/day, smoking (yes/no), sleep (average hours per night), health status ("excellent" to "bad", on a scale of one to five), emotional stress (very little to very much, on a scale of one to five), and height and weight (to calculate body mass index (BMI). Previous exposure to LM education included one "yes/no" question and an estimate of hours spent on LM learning. LM syllabusbased teaching, described in our previous publication [23], is not uniformly delivered in the different LM residency teaching sites. In some sites, residents are exposed to limited LM topics. Residents may be exposed to LM materials in their HMO family department training opportunities. "Trained" residents were considered those who said they attended the LM-specific course or spent $20 \mathrm{~h}$ or more on LM learning.

Sociodemographic items were collected, including age, gender, country of birth, and country of graduation. A copy of the survey is available (in Hebrew) upon request from the authors.

\section{Data analysis}

Data analysis was performed using SPSS Statistic Software version 23.0. Descriptive analyses of variables used counts and percentages for categorical measures and mean and standard deviation (SD) for ordinal measures.

Bivariate analysis was performed using Chi square and Fisher exact tests for categorical variables, and the Mann-Whitney $U$ test for ordinal variables. An explorative $p<0.05$ was considered statistically significant.

We compared health behaviors, attitudes, and confidence in counselling between trained residents (those who participated in a full LM course [23]) versus untrained residents.

We also compared attitudes and confidence between: 1) Residents who are physically active (defined as performing more than $150 \mathrm{~min} /$ week of exercise) and those not physically active, 2) Residents with a BMI of less than 25 versus those with a BMI of more than 25 , and 3) Residents who eat a Mediterranean diet versus those who don't. These comparisons were performed for each attitude and confidence statement separately and also for the composite scores.

Multivariate linear regression analysis was conducted to explore the association between the training and both the mean composite attitude score, and the mean composite confidence score, controlling also for age, gender, place of Medical studies, mean knowledge score, and 
health behaviors (reporting more than $150 \mathrm{~min}$ of physical activity a week, eating a Mediterranean diet, and having a BMI under 25).

\section{Ethics}

This study was approved by the Ben-Gurion University of the Negev's ethics committee (approval \#2016-7, on February 22, 2016). The study was exempted by the ethics committee from signing informed consent forms.

\section{Results}

\section{Study population characteristics}

A total of 169 senior Israeli FM residents were surveyed, and 143 completed the surveys (84.6\% response rate).

The participant's average age was 36.1 years (SD 4.7) (range 29-54), and more than half were women (53.3\%). In addition, $79.9 \%$ were born in Israel and almost half (48.1\%) graduated from medical school in Israel.

Fifty-five participated in a LM course (i.e," trained residents") and 84 ("untrained residents") did not (missing $n=4$ ). No sociodemographic differences were found between "trained" and "untrained" residents (Table 1).

\section{FM residents' health behaviors}

Residents reported performing an average of $115 \mathrm{~min}$ (SD 88.7) of physical activity per week, with an average BMI of 23.9 (SD 4.3) divided into 23 (18/1\%) underweight, 57 (44.9\%) normal weight, 37 (29.1\%) overweight and $10(7.9 \%)$ obese participants (missing 16$)$.

In addition, $72.1 \%$ reported eating a Mediterranean diet at least 3 days a week and $69.8 \%$ reported eating processed foods less than twice a week. Residents reported sleeping for an average of $6.5 \mathrm{~h}$ per night (SD 1.2). Only $6 \%$ were current smokers; $72.1 \%$ reported mild to moderate levels of stress, and $94.3 \%$ described their general health status as mostly good.

\section{FM residents' knowledge}

Of the respondents, $20.1 \%$ ( $n=28$, missing 4$)$ had a high composite knowledge score. Trained residents were significantly more likely to have a high composite knowledge score compared to untrained residents $(30.9 \%$ versus $13.1 \%, p=0.016$ ).

The attitude of FM residents toward their role as healthy lifestyle consultants

Most FM residents (98.6\%) said they believe that LM counseling is part of their role (mean 3.83, SD 0.41) and that LM counseling is effective (82.6\% agreed, mean 3.10, SD 0.69).

As shown in Table 2, compared to untrained residents, trained residents were more likely to agree that physicians have a higher impact on their patients' behavioral changes than other providers (92.6\%, mean 3.26, SD 0.65 and $81 \%$, mean 3.00 , SD $0.66, p<0.01$, respectively). The mean composite attitude score was significantly higher among trained residents compared to untrained residents, (2.97 (SD 0.297) and 2.85 (SD 0.232), respectively; $p=0.006$ ) (Table 2 ). There were no statistically significant differences in mean composite attitude scores regarding participants socio-demographic characteristics (including age, sex, and country of birth), and also for

Table 1 Study population characteristics

\begin{tabular}{|c|c|c|c|c|c|c|c|}
\hline & \multicolumn{2}{|c|}{ Trained residents $(N=55)$} & \multicolumn{2}{|c|}{ Untrained residents $(N=84)$} & \multicolumn{2}{|c|}{ Total $(N=143)$} & \multirow[t]{2}{*}{$p$ value } \\
\hline & $\bar{N}$ & $\%$ & $\bar{N}$ & $\%$ & $\bar{N}$ & $\%$ & \\
\hline \multicolumn{8}{|l|}{ Age } \\
\hline Average \pm SD & $35.9 \pm 4.3$ & & $36.2 \pm 4.9$ & & $36.1 \pm 4.7$ & & 0.680 \\
\hline \multirow[t]{2}{*}{ Range } & $30-50$ & & $29-54$ & & $29-54$ & & \\
\hline & 51 & $(\mathrm{mis}=4)$ & 81 & $(\mathrm{mis}=3)$ & 133 & $(\operatorname{mis}=10)$ & \\
\hline \multicolumn{8}{|l|}{ Gender } \\
\hline Male & 24 & $47.1 \%$ & 38 & $45.8 \%$ & 63 & $46.7 \%$ & 1.000 \\
\hline \multirow[t]{2}{*}{ Female } & 27 & $52.9 \%$ & 45 & $54.2 \%$ & 72 & $53.3 \%$ & \\
\hline & 51 & $(\operatorname{mis}=4)$ & 83 & $(\mathrm{mis}=1)$ & 135 & $(\mathrm{mis}=8)$ & \\
\hline \multicolumn{8}{|l|}{ Country of birth } \\
\hline Israel & 41 & $80.4 \%$ & 65 & $79.3 \%$ & 107 & $79.9 \%$ & 0.999 \\
\hline \multirow[t]{2}{*}{ Abroad } & 10 & $19.6 \%$ & 17 & $20.7 \%$ & 27 & $20.1 \%$ & \\
\hline & 51 & $(\operatorname{mis}=4)$ & 82 & $(\mathrm{mis}=2)$ & 134 & $($ mis $=9)$ & \\
\hline \multicolumn{8}{|c|}{ Medical School graduation } \\
\hline Israel & 25 & $50.0 \%$ & 36 & $46.2 \%$ & 62 & $48.1 \%$ & 0.807 \\
\hline \multirow[t]{2}{*}{ Abroad } & 25 & $50.0 \%$ & 42 & $53.8 \%$ & 67 & $51.9 \%$ & \\
\hline & 50 & $(\mathrm{mis}=5)$ & 78 & $($ mis $=6)$ & 129 & $(\mathrm{mis}=14)$ & \\
\hline
\end{tabular}


Table 2 Family medicine residents' attitudes toward their role as healthy lifestyle consultants

\begin{tabular}{|c|c|c|c|c|c|c|c|c|c|c|}
\hline & \multicolumn{3}{|c|}{$\begin{array}{l}\text { LM trained } \\
\text { residents } \\
(N=55)\end{array}$} & \multicolumn{3}{|c|}{$\begin{array}{l}\text { LM untrained } \\
\text { residents } \\
(N=84)\end{array}$} & \multicolumn{3}{|c|}{ Total $(N=143)$} & \multirow[t]{2}{*}{$P$ value } \\
\hline & Mean & STD & $\mathrm{N}$ & Mean & STD & $\mathrm{N}$ & Mean & STD & $\mathrm{N}$ & \\
\hline Composite attitude score & 2.97 & 0.279 & 55 & 2.85 & 0.232 & 84 & 2.91 & 0.26 & 143 & 0.006 \\
\hline $\begin{array}{l}\text { My profession does not only include treating diseases. } \\
\text { It includes lifestyle counseling, as well. }\end{array}$ & 3.85 & 0.356 & 55 & 3.81 & 0.452 & 84 & 3.83 & 0.416 & 143 & 0.698 \\
\hline Lifestyle counseling is very effective. & 3.22 & 0.686 & 55 & 3 & 0.698 & 83 & 3.1 & 0.698 & 142 & 0.079 \\
\hline $\begin{array}{l}\text { Patients expect physicians to be role models in their } \\
\text { personal health behaviors. }\end{array}$ & 3.47 & 0.604 & 55 & 3.36 & 0.633 & 84 & 3.41 & 0.62 & 143 & 0.281 \\
\hline $\begin{array}{l}\text { Physicians have a higher impact on their patients' } \\
\text { behavioral changes than other providers. }\end{array}$ & 3.26 & 0.65 & 54 & 3 & 0.66 & 79 & 3.11 & 0.665 & 135 & 0.019 \\
\hline \multicolumn{11}{|l|}{$\begin{array}{l}\text { Patients can be motivated to change their behaviors, } \\
\text { including: }\end{array}$} \\
\hline Smoking cessation & 3.04 & 0.576 & 55 & 3.02 & 0.514 & 84 & 3.03 & 0.53 & 143 & 0.884 \\
\hline Losing weight & 3.09 & 0.591 & 54 & 3 & 0.609 & 82 & 3.03 & 0.603 & 138 & 0.418 \\
\hline Engaging in physical activity & 3.11 & 0.577 & 53 & 2.91 & 0.592 & 82 & 2.99 & 0.588 & 137 & 0.063 \\
\hline \multicolumn{11}{|l|}{$\begin{array}{l}\text { Many physicians do not guide their patients toward } \\
\text { a healthy lifestyle because: }\end{array}$} \\
\hline They do not believe in the effectiveness of counseling. & 2.55 & 0.741 & 55 & 2.34 & 0.741 & 82 & 2.43 & 0.75 & 140 & 0.123 \\
\hline Employers do not compensate for counseling. & 2.65 & 0.731 & 54 & 2.43 & 0.821 & 81 & 2.53 & 0.794 & 138 & 0.095 \\
\hline Residents lack relevant knowledge. & 2.62 & 0.828 & 55 & 2.37 & 0.679 & 81 & 2.47 & 0.745 & 139 & 0.071 \\
\hline It is not a part of their job. & 2.09 & 0.701 & 55 & 2.06 & 0.705 & 83 & 2.09 & 0.702 & 141 & 0.994 \\
\hline It is less interesting to them. & 2.53 & 0.663 & 55 & 2.48 & 0.82 & 82 & 2.51 & 0.763 & 140 & 0.801 \\
\hline They lack time. & 3.31 & 0.639 & 54 & 3.21 & 0.646 & 81 & 3.26 & 0.645 & 137 & 0.366 \\
\hline
\end{tabular}

Range: 1-4; 1- definitely do not agree, 4 - definitely agree. * $P$ value for $L M$-trained residents versus residents not trained in $L M$

the mean composite knowledge score. Israeli medical graduates had significantly higher mean composite attitude scores $(n=62,2.98$ [SD 0.246]), compared to participants conducting their medical studies abroad $(n=67,2.84$ [SD 0.268]) $(p=0.002)$.

\section{FM residents' confidence in LM consultation}

Less than half $(42.1 \%)$ of the residents reported that they felt confident or absolutely- confident in their ability to support patients' lifestyle behavior changes. Trained residents reported a significantly higher proportion of feeling confident or absolutely confident, as compared to untrained residents (53.7\% vs. $34.5 \%, p=0.004)$.

Confidence in the ability to provide LM counselling was significantly higher in trained residents in general, especially with regard to physical activity, obesity and nutrition, as compared to untrained residents (Table 3 ).

The mean composite confidence score for trained residents was significantly higher compared to untrained residents (2.89 [SD 0.435] and 2.68 [SD 0.432] respectively; $p=0.008$ ) (Table 3 ). No difference was found in the mean composite confidence score for all the sociodemographic characteristics, including place of medical studies (Israel or abroad), or mean composite knowledge score. There was a weak positive correlation between the age of the participants and their mean composite confidence scores $(r=0.213, p=0.014)$.

Association between residents' health behavior, attitudes, and confidence toward LM counselling

There was a significant difference in the mean composite attitude scores between participants who were physically active vs those reporting performing $<150 \mathrm{~min}$ of physical activity per week (3.04 [SD 0.294] and 2.89 [SD $0.225]$, respectively; $p=0.005$ ); between participants with $\mathrm{BMI}<=25$ vs. those with BMI $>=25$ (2.95 [SD 0.261[and 2.83 [SD 0.255] respectively; $p=0.01$ ); and between participants reporting eating a Mediterranean diet vs. those who did not (2.94 [SD 0.282] and 2.82 [SD 0.183] respectively; $p=0.011)$.

Residents who are physically active, have a $\mathrm{BMI}<25$, and ate a Mediterranean diet most days of the week had a significant higher confidence in their ability to provide patients with knowledge and skills to change their unhealthy lifestyle (Table 4).

For the mean composite confidence score, only those reporting eating a Mediterranean diet had significantly higher confidence scores vs those reporting not eating a Mediterranean diet (2.83 [SD 0.459] and 2.60 [SD 0.348], respectively; $p=0.005$ ). 
Table 3 Family medicine residents' assessment of confidence in healthy LM consultations

\begin{tabular}{|c|c|c|c|c|c|c|c|c|c|c|}
\hline & \multicolumn{3}{|c|}{$\begin{array}{l}\text { LM trained } \\
\text { residents } \\
(N=55)\end{array}$} & \multicolumn{3}{|c|}{$\begin{array}{l}\text { LM un-trained } \\
\text { residents } \\
(N=84)\end{array}$} & \multicolumn{3}{|c|}{ Total $(N=143)$} & \multirow[t]{2}{*}{$P$ value } \\
\hline & Mean & STD & $\mathbf{N}$ & Mean & STD & $\mathbf{N}$ & Mean & STD & $\mathrm{N}$ & \\
\hline Composite confidence score & 2.89 & 0.435 & 54 & 2.68 & 0.432 & 83 & 2.77 & 0.44 & 137 & 0.008 \\
\hline $\begin{array}{l}\text { In general, it is easy to incorporate lifestyle counseling } \\
\text { into the clinic's daily routine. }\end{array}$ & 2.67 & 0.777 & 54 & 2.53 & 0.77 & 83 & 2.59 & 0.769 & 139 & 0.248 \\
\hline $\begin{array}{l}\text { I have the knowledge to promote a healthy lifestyle to } \\
\text { my patients. }\end{array}$ & 2.98 & 0.658 & 54 & 2.73 & 0.646 & 83 & 2.84 & 0.662 & 139 & 0.024 \\
\hline \multicolumn{11}{|l|}{$\begin{array}{l}\text { I can provide my patients with enough knowledge and } \\
\text { skills to change the following behaviors: }\end{array}$} \\
\hline Cigarette smoking & 2.91 & 0.708 & 54 & 2.73 & 0.7 & 83 & 2.81 & 0.711 & 139 & 0.154 \\
\hline Obesity & 3.09 & 0.652 & 54 & 2.83 & 0.601 & 83 & 2.94 & 0.634 & 139 & 0.019 \\
\hline Physical inactivity & 3.2 & 0.562 & 54 & 2.89 & 0.585 & 83 & 3.02 & 0.595 & 139 & 0.003 \\
\hline Sleep disturbance & 2.67 & 0.824 & 54 & 2.64 & 0.636 & 83 & 2.65 & 0.711 & 139 & 0.812 \\
\hline Stress & 2.78 & 0.718 & 54 & 2.58 & 0.718 & 83 & 2.65 & 0.719 & 139 & 0.093 \\
\hline Sexuality & 2.41 & 0.714 & 54 & 2.17 & 0.721 & 81 & 2.28 & 0.725 & 137 & 0.023 \\
\hline Unhealthy eating & 3.15 & 0.684 & 54 & 2.84 & 0.573 & 83 & 2.96 & 0.63 & 139 & 0.007 \\
\hline
\end{tabular}

Range: 1-4; 1 - definitely do not agree, 4 - definitely agree

${ }^{*} P$ value for $L M$ - trained residents versus residents not trained in LM

Results from multivariate linear regression show that performing more than 150 min a week of physical activity (beta 0.175 [SE 0.06], 95\% CI 0.055, 0.296, $p=0.005$ ); eating a Mediterranean diet (beta 0.137 [SE 0.065], 95\% CI 0.007, 0.267, $p=0.039$ ); and completing medical school in Israel (beta 0.142 [SE 0.059], 95\% CI 0.024, $0.259, p=0.019)$ were found to be significant predictors of a higher mean composite attitude score.

Eating a Mediterranean diet (beta 0.258 [SE 0.117], 95\% CI 0.024, 0.492, $p=0.031$ ); completing medical school in Israel (beta -0.293 [SE 0.105], 95\% CI -0.502, $-0.084, p=0.007$ ); and the age of the participant (beta 0.022 [SE 0.011], 95\% CI 0.001, 0.044, $p=0.039$ ); were found to be significant predictors of a higher mean composite confidence score (Table 5 ).

\section{Discussion}

The aims of this study were: 1) to assess the knowledge level, attitudes, and confidence of senior Israeli FM residents in regard to LM counseling, and 2) to evaluate the influence of training in an LM course and personal health behaviors on resident's' knowledge, attitudes, and confidence.

We delivered a nationwide survey of Israeli senior FM residents (those attending their third or fourth residency year) to assess their levels of knowledge, attitudes, and confidence with regard to LM counseling, along with the effects of LM training and personal health behaviors on those levels. Our response rate was $85 \%$, higher than typically achieved in a physician population [26].
Our results show that senior FM residents consider LM counseling to be an integral part of their role and an effective tool by which to improve a patient's health. Yet, their LM knowledge level and the confidence to deliver that knowledge are low.

Trained residents had a higher level of LM knowledge and were more confident in their ability to succeed and impact a patient's behavioral changes. However, in the multivariate linear regression models, participation in the LM training was not found to be a significant predictor of either the mean composite attitude or confidence score. Personal health behaviors (such as eating a Mediterranean diet) and completing medical school in Israel were found to be significant predictors of both the mean composite attitude and confidence scores.

Personal positive health behaviors were correlated with a higher level of confidence to provide patients with knowledge and skills to change their unhealthy lifestyles.

In a study of Ohio primary care residents, scores of attitude and self-efficacy regarding obesity, nutrition, and physical activity counseling were low [27]. Another study of U.S. residents $(n=101)$ areas found that only 19\% felt competent in prescribing weight-loss programs [28].

In our study, trained residents based on the Israeli LM syllabus [29] had a higher level of LM knowledge and were more confident in their ability to help patients change. Yet, in the multivariate linear regression models, LM training was not found to be a significant predictor of high confidence level. Our previous study demonstrated that immediately after a LM course, trainings 
Table 4 Association between residents' health behavior, attitudes, and confidence levels with respect to LM counseling

\begin{tabular}{|c|c|c|c|c|c|c|c|}
\hline \multirow[t]{2}{*}{ Physical activity } & \multicolumn{3}{|c|}{$\begin{array}{l}\text { Physical activity more } \\
\text { than } 150 \mathrm{~min} / \text { week } \\
(N=29)\end{array}$} & \multicolumn{3}{|c|}{$\begin{array}{l}\text { Physical activity less } \\
\text { than } 150 \text { min/week } \\
(N=78)\end{array}$} & \multirow[t]{2}{*}{$P$ value } \\
\hline & Mean & STD & N & Mean & STD & N & \\
\hline In my personal life, I lead a healthy lifestyle. & 3.48 & 0.57 & 29 & 2.91 & 0.56 & 78 & $<0.0001$ \\
\hline I think patients can be persuaded to lose weight. & 3.24 & 0.58 & 29 & 2.97 & 0.58 & 77 & 0.038 \\
\hline I think patients can be persuaded to exercise regularly. & 3.21 & 0.57 & 28 & 2.97 & 0.51 & 77 & 0.041 \\
\hline \multirow[t]{2}{*}{ BMI } & \multicolumn{3}{|c|}{$\mathrm{BMl}<25(\mathrm{~N}=80)$} & \multicolumn{3}{|c|}{$\mathrm{BMI}>25(\mathrm{~N}=47)$} & $P$ value \\
\hline & Mean & STD & N & Mean & STD & N & \\
\hline In my personal life, I lead a healthy lifestyle. & 3.18 & 0.57 & 80 & 2.62 & 0.57 & 47 & $<0.0001$ \\
\hline I think patients can be persuaded to lose weight. & 3.14 & 0.55 & 78 & 2.85 & 0.66 & 47 & 0.013 \\
\hline I think patients can be persuaded to exercise regularly. & 3.09 & 0.54 & 78 & 2.85 & 0.67 & 46 & 0.038 \\
\hline $\begin{array}{l}\text { I'm sure I can give patients enough knowledge and skills } \\
\text { to improve an unhealthy diet. }\end{array}$ & 3.05 & 0.62 & 78 & 2.79 & 0.66 & 47 & 0.026 \\
\hline \multirow[t]{2}{*}{ Mediterranean diet } & \multicolumn{3}{|c|}{$\begin{array}{l}\text { Eat Mediterranean diet } \\
\text { most days of the week }\end{array}$} & \multicolumn{3}{|c|}{$\begin{array}{l}\text { Do not eat Mediterranean } \\
\text { diet most days of the week } \\
(N=39)\end{array}$} & $P$ value \\
\hline & Mean & STD & N & Mean & STD & N & \\
\hline In my personal life, I lead a healthy lifestyle. & 3.07 & 0.62 & 101 & 2.69 & 0.61 & 39 & 0.002 \\
\hline Counseling for a healthy lifestyle is very effective. & 3.02 & 0.7 & 100 & 3.33 & 0.66 & 39 & 0.016 \\
\hline $\begin{array}{l}\text { In general, it is easy to include LM counseling as part of } \\
\text { clinic activities. }\end{array}$ & 2.67 & 0.8 & 101 & 2.37 & 0.63 & 38 & 0.056 \\
\hline \multicolumn{8}{|l|}{$\begin{array}{l}\text { I can provide my patients with enough knowledge and } \\
\text { skills to change the following behaviors: }\end{array}$} \\
\hline Cigarette smoking & 2.9 & 0.73 & 101 & 2.55 & 0.6 & 38 & 0.019 \\
\hline Obesity & 3.01 & 0.66 & 101 & 2.76 & 0.54 & 38 & 0.044 \\
\hline Physical inactivity & 3.1 & 0.59 & 101 & 2.82 & 0.56 & 38 & 0.012 \\
\hline Sleep disturbance & 2.73 & 0.75 & 101 & 2.42 & 0.55 & 38 & 0.031 \\
\hline Unhealthy eating & 3.06 & 0.65 & 101 & 2.71 & 0.52 & 38 & 0.004 \\
\hline I have the knowledge to promote a healthy lifestyle to my patients. & 2.91 & 0.66 & 101 & 2.66 & 0.63 & 38 & 0.09 \\
\hline
\end{tabular}

Range: 1-4; 1 - definitely do not agree, 4 - definitely agree

* $P$ value for residents with healthy behaviors versus residents withhealth behaviors below recommendation levels

Table 5 Multivariate linear regression model regarding Attitude and confidence

\begin{tabular}{|c|c|c|c|c|c|}
\hline & & \multirow[t]{2}{*}{ OR } & \multirow[t]{2}{*}{ Sig. } & \multicolumn{2}{|l|}{$95 \% \mathrm{Cl}$} \\
\hline & & & & Lower Bound & Upper Bound \\
\hline \multirow[t]{4}{*}{ Attitude } & Physical activity of more than 150 min per week & 0.314 & 0.002 & 0.073 & 0.299 \\
\hline & age (years) & -0.129 & 0.186 & -0.017 & 0.003 \\
\hline & gender (male) & 0.008 & 0.934 & -0.097 & 0.105 \\
\hline & Medical school graduation & 0.316 & 0.002 & 0.062 & 0.265 \\
\hline \multirow[t]{4}{*}{ Confidence } & age (years) & 0.173 & 0.042 & 0.001 & 0.033 \\
\hline & gender (male) & 0.091 & 0.298 & -0.073 & 0.236 \\
\hline & Eating a Mediterranean diet & 0.325 & 0.000 & 0.154 & 0.492 \\
\hline & Medical school graduation & -0.184 & 0.042 & -0.322 & -0.006 \\
\hline
\end{tabular}


improve residents' knowledge levels and confidence in delivering LM [23].

We are aware of the low number of trained residents passing the knowledge test and their therefore appropriately limited confidence in their ability to deliver LM interventions. This may mean that more in-depth training is needed to achieve better results. The challenge is to prioritize effective LM education as an essential part of FM residency.

The LM-positive attitude of Israeli FM residents is an important finding, since it implies that there is no need to convince them of the importance of LM.

Lifestyle behaviors of Israeli FM residents are mostly healthy, which is consistent with FM physicians in the United States [27] and better than lifestyle behaviors of Israeli physicians in general [24]. FM residents see themselves as role models for their patients, and the high correlation we found between residents' lifestyle behaviors and their perceived efficacy to impact patients demonstrates it. Prior studies have presented similar findings of a strong and consistent relationship between physicians' and their patients' health behaviors $[15,16,18]$, and recommend investing in physicians' health as an efficient and beneficent way to increase high-quality LM counseling and more distal patient outcomes [15, 16, 18, 30]. These findings that the residents' personal health behaviours were correlated with their LM related attitudes and confidence, also support the need to invest in physicians' personal health.

This study has a few limitations. First, the knowledge questionnaire was not validated and thus might not reflect actual knowledge well. Yet, it was created from a peer-reviewed FM board exam questionnaire and reviewed by experts in the field who teach in residents' LM courses. Therefore, we believe the questions are reliable. Second, the data collected were based on selfreport, including self-reported lifestyle behaviors and residents' recollections of the amount of LM training. This is similar to other studies in this field, but we cannot rule out reporting bias around attitudes and behaviors and an incorrect recollection of the amount of LM training. Third, this study did not track LM counseling in residents' clinics with real patients. After evaluating residents' perceptions about LM counseling and the feasibility of LM training in Israel, our next step will be to conduct a randomized controlled trial to evaluate the impact of LM training, with a personal health promotion component, on residents' actual counseling skills and practices. This has been shown in one four-year-long medical school intervention to be effective [30-32], but never with residents or practicing physicians.

We are in the beginning of offering widely scaled LM education programs [33]; such can be found here at the Life styleMedicineEducation.org/curricular resources/ website. It is clear that such offerings can help developing training programs for physicians in order to enhance the health of the population.

\section{Conclusions}

FM plays a key role in the management of patients with chronic diseases. Israeli FM residents consider consulting on healthy lifestyles to be an integral part of their work, but they are not well prepared to do so. This LM training improved these residents' knowledge levels, but not their attitude nor their confidence to deliver LM -- but personal health behaviors improved residents' attitude and confidence scores.

In depth dedicated LM competency-based training [33] and resident personal health promotion can improve levels of LM counseling and patient outcomes.

We recommend encouraging an expanded LM course in FM residency educational programs in Israel and abroad [33], with a significant investment to promote residents' personal health;

Further studies are needed to examine the effect of training on patient health outcomes.

\section{Abbreviations}

FM: Family medicine; LM: Lifestyle medicine; NCDs: Non-communicable diseases; HMOs: Health maintenance organizations; BMI: Body mass index; SD: Standard deviation

\section{Acknowledgements}

The authors thank the previous Chairman of the Israeli Association of Family Physicians, Prof. Shlomo Vinker, for his ongoing support, and Tamar Freud, PhD, Research Manager, and Ilona Kolushov from the Siaal Research Center, for FM and primary care-related contributions and for performing the statistical analysis. We thank Deb Holmes for her editing assistance, and the UBC Canada Research Chair program and Annenberg Physician Training Program for their support of this research through Dr. Frank.

\section{Authors' contributions}

LM, RP, EF, and AT-O designed the study. LM and AT-O were responsible for conducting the study. YBZ advised regarding methodology and data analysis. LM drafted the manuscript, and EF significantly revised multiple manuscript revisions. All authors critically reviewed the manuscript and approved the final version.

\section{Funding}

The research was funded by the Israeli Association of Family Physicians which supported the research assistants and statistician time with EF's efforts supported by the Canada Research Chair in Preventive Medicine and Population Health, and the Annenberg Physician Training Program in Addictive Disease.

Availability of data and materials

Data can be made available on request from the corresponding author, following approval from the study's approving ethics committee.

\section{Ethics approval and consent to participate}

This study was approved by the Ben-Gurion University of the Negev's ethics committee (approval \#2016-7 on February 22, 2016). The study was exempted by the ethics committee from signing informed consent forms.

\section{Consent for publication}

Not Applicable.

Competing interests

All authors - LM, YBZ, RP, EF, and AT-O- declare that they have no competing interests. 


\section{Author details}

Israeli Society of Lifestyle Medicine, Israeli Association of Family Physicians, Tel Aviv, Israel. ${ }^{2}$ Siaal Research Center for Family Medicine and Primary Care, Department of Family Medicine, Faculty of Health Sciences, Ben-Gurion University of the Negev, POB 653, 84105 Beer-Sheva, Israel. ${ }^{3}$ NextGenU.org, Nanoose Bay, British Columbia, Canada and Clear Lake, Washington, USA. ${ }^{4}$ Braun School of Public Health and Community Medicine, Hebrew University of Jerusalem, Jerusalem, Israel. ${ }^{5}$ Department of Physical Medicine \& Rehabilitation, Harvard Medical School, Spaulding Rehabilitation Hospital, Boston, MA, USA. ${ }^{6}$ Center of Lifestyle Medicine, Sheba Medical Center, Tel Hashomer, Israel. 'Faculty of Medicine, University of British Columbia, Vancouver, Canada.

Received: 2 August 2018 Accepted: 2 September 2020

Published online: 11 September 2020

\section{References}

1. Global status report on noncommunicable diseases 2010 http://apps.who. int/iris/bitstream/10665/44579/1/9789240686458_eng.pdf.

2. Israel National Health Interview Survey INHIS-3 2013-2015 https://www. health.gov.il/publicationsfiles/inhis_3.pdf.

3. Knowledge, Attitude and Practices (KAP) national survey, the Department of Health Education and Health Promotion in the Ministry of Health, Israel, 2013. https://www.health.gov.il/publicationsfiles/kap2013.pdf.

4. Mokdad AH, Marks JS, Stroup DF, Gerberding JL. Actual causes of death in the United States, 2000. JAMA. 2004;291(10):1238-45.

5. Li Y, Pan A, Wang DD, Liu X, Dhana K, Franco OH, Kaptoge S, Di Angelantonio E, Stampfer M, Willett WC, Hu FB. Impact of Healthy Lifestyle Factors on Life Expectancies in the US Population. Circulation. 2018;117:032047. https://doi.org/10.1161/CIRCULATIONAHA.117.032047 [Epub ahead of print].

6. Lianov L, Johnson M. Physician competencies for prescribing lifestyle medicine. JAMA. 2010;304:202-3.

7. Jacobson DM, Strohecker L, Compton MT, Katz DL. Physical activity counseling in the adult primary care setting: position statement of the American College of Preventive Medicine. Am J Prev Med. 2005;29:158-62.

8. Kreuter MW, Shobhina G. How does physician advice influence patient behavior? Evidence for a priming effect; Chheda, MD, MPH; Fiona C. bull, PhD. Arch Fam Med. 2000:9:426-33.

9. Peek ME, Tang H, Alexander GC, Chin MH. National prevalence of lifestyle counseling or referral among African-Americans and whites with diabetes. J Gen Intern Med. 2008;23:1858-64.

10. Baron-Epel O. Consumer-oriented evaluation of health education services. Patient Educ Couns. 2003;49(2):139-47. https://doi.org/10.1016/S07383991(02)00073-3.

11. Barnes PM, Schoenborn CA. Trends in adults receiving a recommendation for exercise or other physical activity from a physician or other health professional. NCHS Data Brief. 2012;86:1-8 http://www.ncbi.nlm.nih.gov/ pubmed/22617014.

12. Rosenberg E, Lev B, Bin-Nun G, McKee M, Rosen L. Healthy Israel 2020: a visionary national. Health targeting initiative. Public Health. 2008;122(11): 1217-25.

13. Dysinger $\mathbf{W}$. Lifestyle medicine competencies for primary care physicians. Virtual Mentor. 2013:15(4):306-10.

14. Egger GJ, Binns A, Rossner S. Lifestyle medicine. New York: McGrawHill; 2008.

15. Oberg EB, Frank E. Physicians' health practices strongly influence patient health practices. J R Coll Physicians Edinb. 2009;39(4):290-1.

16. Frank E, Dresner $Y$, Shani M, Vinker S. The association between physicians' and patients' preventive health practices. CMAJ. 2013;185:649-53.

17. Frank E, Breyan J, Elon L. Physician disclosure of healthy personal behaviors improves credibility and ability to motivate. Arch Fam Med. 2000;9:287-90

18. WMA Statement on Physicians Well-Being. 21st February 2017. https://www wma.net/policies-post/wma-statement-on-physicians-well-being/.

19. Hivert MF, Arena R, Forman DE, Kris-Etherton PM, McBride PE, Pate RR, Spring B, Trilk J, Van Horn LV, Kraus WE. Medical training to achieve competency in lifestyle counseling: an essential foundation for prevention and treatment of cardiovascular diseases and other chronic medical conditions: a scientific statement from the American heart association. Circulation. 2016;134:e308-27.
20. The Lifestyle Medicine Residency Curriculum (LMRC). American College of Lifestyle Medicine (ACLM). https://lifestylemedicine.org/ACLM/Education/ Residency_Curriculum/ACLM/Education/Residency_Curriculum.aspx?hkey= 44673c28-cc4f-4bd8-89b8-1d66faa5b40d.

21. Syllabus for the study of lifestyle medicine. The Society of Lifestyle Medicine, Israel Association of Family Physicians, The Israeli Medical Association. August 2014. https://cdn.mednet.co.il/2015/08/syllabus-lifestylemedicine.pdf.

22. Dagan I. Primary care physicians' attitudes towards promoting a healthier lifestyle: the barriers and promoters to lifestyle counseling. Diss: University of Haifa, Faculty of Social Welfare \& Health Studies, School of Public Health; 2006.

23. Malatskey L, Bar Zeev Y, Tzuk-Onn A, Polak R. Lifestyle medicine course for family medicine residents: preliminary assessment of the impact on knowledge, attitudes, self-efficacy and personal health; Postgrad Med J 2017;0:1-6.

24. Wilf-Miron R, Malatskey L, Rosen L, Peled R. Health-related behaviors and perceptions among physicians: results from a cross-sectional study. BMJ Open. 2019;9:e031353. https://doi.org/10.1136/bmjopen-2019-031353.

25. Zaragoza-Martí A, Cabañero-Martínez MJ, Hurtado-Sanchez JA, Laguna-Perez A, Ferrer-Cascales R. Evaluation of Mediterranean diet adherence scores: a systematic review. BMJ Open. 2018;8:e019033 https://bmjopen.bmj.com/ content/8/2/e019033\#ref-11.

26. Grava-Gubins I, Scott S. Effects of various methodologic strategies: survey response rates among Canadian physicians and physicians-in-training. Can Fam Physician. 2008:54:1424-30.

27. Smith S, Seeholzer EL, Gullett H, Jackson B, Antognoli E, Krejci SA, Flocke SA Flocke (2015) primary care Residents' knowledge, attitudes, self-efficacy, and perceived professional norms regarding obesity, nutrition, and physical activity counseling. J Grad Med Edu. 2015;7(3):388-94.

28. Davis NJ, Shishodia H, Taqui B, Dumfeh C, Wylie-Rosett J. Resident physician attitudes and competence about obesity treatment: need for improved education. Med Educ Online. 2008;13:5.

29. Syllabus for the study of lifestyle medicine. http://www.ima.org.il/ mainsitenew/editclinicalinstruction.aspx?clinicalinstructionid=235.

30. Vickers KS, Kircher KJ, Smith MD, Petersen LR, Rasmussen NH. Health behavior counseling in primary care: provider-reported rate and confidence. Fam Med. 2007:39(10):730-5.

31. Frank E, Elon L, Hertzberg V. Quantitative assessment of a 4-year intervention that improved patient counseling through improving medical student health. Medscape Gen Med. 2007;9(2):58 http://www.medscape. com/viewarticle/557088

32. Frank E, Smith D, Fitzmaurice D. 2005. A description and qualitative assessment of a 4 year intervention to improve medical student health. Medscape General Medicine. http://www.medscape.com/viewarticle/501770.

33. Rossa-Roccor V, Malatskey L, Frank E. NextGenU.org's Free, Globally Available Online Training in Lifestyle Medicine NextGenU.org's. Am J Lifestyle Med. 2017. https://doi.org/10.1177/1559827616682444

\section{Publisher's Note}

Springer Nature remains neutral with regard to jurisdictional claims in published maps and institutional affiliations.

Ready to submit your research? Choose BMC and benefit from:

- fast, convenient online submission

- thorough peer review by experienced researchers in your field

- rapid publication on acceptance

- support for research data, including large and complex data types

- gold Open Access which fosters wider collaboration and increased citations

- maximum visibility for your research: over $100 \mathrm{M}$ website views per year

At BMC, research is always in progress.

Learn more biomedcentral.com/submissions 